\title{
Modeling Wind-Turbine Power Curves: Effects of Environmental Temperature on Wind Energy Generation
}

\author{
Miguel Á. Rodríguez-López ${ }^{1}$, Emilio Cerdá ${ }^{1}$ and Pablo del Rio ${ }^{2, *}$ \\ 1 Instituto Complutense de Estudios Internacionales (ICEI), Complutense University of Madrid, \\ 28040 Madrid, Spain; migrod11@ucm.es (M.Á.R.-L.); ecerdate@ccee.ucm.es (E.C.) \\ 2 Consejo Superior de Investigaciones Científicas (CSIC), Institute of Public Policies and Goods (IPP), \\ C/Albasanz, 26-28, 28037 Madrid, Spain \\ * Correspondence: Pablo.delrio@csic.es
}

Received: 29 July 2020; Accepted: 15 September 2020; Published: 21 September 2020

\begin{abstract}
Global warming represents a serious challenge, which requires the adoption of renewable energy technologies worldwide. However, it can negatively affect the availability of renewable energy resources, such as wind, which are needed for electricity generation. In this context, there is an increasing need for more accurate evaluations of wind turbine power curves. A novel methodology to model the power curves of wind turbines, which combines the use of artificial neural networks (ANN) and Fuzzy logic rules, is proposed in this paper. This methodology assesses the role of environmental temperature in the power curve and the impact of temperature increases on wind energy production. The application of this methodology is illustrated with the simulation of the impact of global warming on the electricity generation of a wind farm. Due to the non-linear relationship between the power output of a turbine and its primary and derived parameters, it is shown that ANN combined with an expert system formed by a Fuzzy logic module fit power curve modeling processes well. The application of the methodology shows that an increase in temperatures would trigger a small reduction in the performance of wind turbines.
\end{abstract}

Keywords: wind turbine; power curve; global warming; electricity generation; artificial neural networks

\section{Introduction}

Climate change represents a serious global challenge. Global surface temperatures have reached unprecedented levels [1]. As is well-known, the accumulation of greenhouse gas emissions (GHG) is directly related to the combustion of fossil fuels in all sectors of the economy, notably electricity generation, transport and industry.

Climate change mitigation will require the adoption of decarbonization strategies everywhere, e.g., in all sectors and countries. Concern about climate change has led to the Paris Agreement, in which governments committed to reducing those emissions in order to keep a global temperature rise well below 2 degrees Celsius $\left({ }^{\circ} \mathrm{C}\right)$ above pre-industrial levels and to pursue efforts to limit the temperature increase to $1.5^{\circ} \mathrm{C}$ [1]. This entails a considerable reduction in emissions, around $50 \%$ in 2050 compared to 1990 levels [2].

Actions will need to be taken in order to improve the energy efficiency of production and consumption patterns and to increase the uptake of low carbon technologies. In this context, it is a widely shared view that the deployment of renewable energy technologies (RETs) is a critical alternative to abate GHG emissions, whose accumulation leads to global warming. 
According to the IEA 2DS scenario, the installed wind capacity will need to increase from the $433 \mathrm{GW}$ in 2015) [3,4] to 2.7-3.5 TW [5,6] in 2050. The total investment in wind power required in the 2DS scenario would be USD 3.45 trillion (2018 USD) [6].

However, global warming can negatively affect the availability of renewable energy resources, such as wind, which are needed in order to generate electricity with those technologies. Focusing on the case of wind energy, a reduction in the performance of a wind turbine due to thermal losses, operational behavior changes and a change in air density in the location caused by global warming will reduce the number of full-load hours of the wind farm. This will decrease the amount of electricity generation in the existing and new installations.

The purpose of this article is to develop a methodology to evaluate the impact of environmental temperature on wind energy generation and to simulate the losses in a real wind farm.

The power curve (PC) of a wind turbine is a relationship that describes the power output for a given wind speed [7]. The PC is currently used in the energy sector to estimate the annual production in a given location. It is a part of the control system which tries to capture most of the energy from the wind $[8,9]$, and a tool to monitor the quality or condition of the wind turbines $[10,11]$.

The industry standard for PC estimation based on a field test is the IEC PC, which was developed by the International Electrotechnical Commission (IEC) and described in IEC 61400-12-1 (2005). Here, wind speed and generated power used for curve representation are 10-min average values, with the purpose of reducing the effect of outliers, noise and serial correlation [12].

However, it has been criticized that the IEC estimate ignores the non-linearity of the ideal PC [13]. This paper analyses the effect of external temperature on the non-linearity of the PC through artificial neural network (ANN) models. A novel methodology which combines the use of ANN and Fuzzy logic rules in order to model the power curves of a set of wind turbines is proposed. The application of this methodology is then illustrated with a simulation of the impact of global warming on the electricity generation of a wind farm.

ANN models are generally parametric or non-parametric. The parametric models are built from a set of mathematical equations that include parameters that must be adapted through a set of continuous data [14]. Parametric methods generally use linear, non-linear, polynomial and differential equations.

With the recent arrival of powerful databases and data science techniques, new modeling methods have emerged. Instead of assuming a physical or analytical relationship between the input and the output data, the non-parametric methods set up correlations based only on the data provided [14]. The main advantage of these non-parametric models with respect to previous methodologies lies in the fact that it is not necessary to know the nature of the dataset to be represented. Rather, the ANN itself gathers the essential characteristics of such dataset through the training process [15]. Other advantages include:

- Nonlinearity: the nonlinear behavior of the functions of activation of the neurons will enable the neural networks to act as universal proxies of nonlinear functions.

- They can be adapted to the development of any type of data representation by just retraining them. In contrast to physical models [16], they are less dependent on the knowledge of the "experts" for model development.

Recent efforts were mainly oriented toward the improvement of the evaluation of the actual power performance. Helbing and Ritter [7] provided a methodology for improving the wind turbine power curve with standardization. The authors developed a parametric model taking into account the role of wind turbulence in the power curve. Fan and Zhu [17] developed an optimization method of the power curve based on a parametric approach to solve the problems of large wind speed variation and low wind turbine efficiency in low wind-speed regions. Lydia et al. [18] proposed a methodology for wind resource estimation using predictive models based on ANN. It was built using exogenous variables (NLARX) combined with power curves modeled with a five parametric logistic equation. The values of the parameters were assessed with differential evolution (DE). Marčiukaitis et al. [19] proposed a non-lineal regression to model the ramp of the power curve. The model had several advantages, 
such as the fitting of the physical properties of the wind turbine (i.e., the power curve does not exceed the highest value generated power as it is the physically possible maximum) and the dependency with other variables such as wind direction. Pelletier et al. [14] used multilayer perceptron ANN to model the wind turbine power curve, reducing the error of the model compared to IEC methods. In their study, power curves at the wind farm level were modeled using six operational parameters, such as air density, turbulence intensity or wind shear. These authors also designed a complex system with several ANN. Ouyang et al. [20] used support vector machine (SVM) algorithms to build a power curve model. In their study, the authors identified three representative points of the power curve that divide it into four regions with a completely different behavior.

Regarding energy losses in the wind farm due to environmental changes, previous contributions have analyzed the impact of climate change on electricity generation with RETs in general and wind energy in particular. Pryor and Barthelmie [21] provided a review proposing possible mechanisms through which global climate variability and change could influence wind energy resources. They concluded that evidence for small magnitude changes could only appear by the end of the twenty-first century. In more recent studies, Fant et al. [22] presented a methodology based on the combination of the risk-based climate projection from the Integrated Global System Model (IGSM) and data from the Coupled Model Interpolation Project (CMIP-3). Their results show that significant changes in wind speed resources cannot be expected by 2050. Similar conclusions were reached by Davy et al. [23] in their assessment based on the use of a single-model-ensemble from the Rossby Centre (RCA4). Notwithstanding, using models from the HAPPI project and taking into account the distributions of sub-daily viability, the height of the wind turbine and power losses due to the grids, Scott Hosking et al. [24] concluded that the potential for wind energy in some regions may be greater than previously thought, considering a scenario of a $1.5^{\circ} \mathrm{C}$ warmer world.

Compared to those contributions, this paper advances knowledge on several fronts. It provides a methodology to model the wind turbines power curve for the assessment of production losses, using a combination of ANNs and Fuzzy logic rules. This combined system takes into account the effect of the control system on the power curve model, whereas this effect is disregarded in the previous literature [7,17-19]. If this effect is not included, then a poor adjustment in the transition parts of the power curve results. Second, although previous studies consider air density as a parameter in their model, the environmental temperature is used in this paper as a parameter with an indirect relation with air density. Our methodology reduces the number of input variables which are needed in order to take into account the effect of air density from five [18] or six [14] to just one. This is useful since the air density measurement during the resource evaluation process may be available for wind farms, but not during the whole life cycle of the asset. Third, a two-stage model (formed by two ANN in cascade) was used to simulate the production in the ramp of the power curve. In contrast, only one ANN or SVM $[14,20]$ model was used to characterize this part of the power curve in the previous literature. Fourth, an analysis of the impact of global warming on wind energy production is carried out, using a model of wind energy generation based on ANN. The energy and economic losses in the wind farm used for this study have been assessed. Whereas simulations are mostly carried at macroscopic level in the literature and special attention to environmental temperature is not given, different scenarios with several increases in environmental temperature due to global warming at wind farm level are simulated in this paper.

Accordingly, the paper is structured as follows. Section 2.1 briefly describes ANN and Fuzzy logic techniques. The methodology developed in this article to assess the relationship between energy production and temperature is elaborated in Section 2.2. Section 2.3 describes the analytical model. The methodology is illustrated with an application in Section 3, where simulations of performance losses under different environmental conditions, as well as the economic losses in the wind farm, are provided. The paper closes with some conclusions and suggestions for future research. 


\section{Materials and Methods}

\subsection{A Description of Modeling Methods}

\subsubsection{Artificial Neural Networks (ANN)}

Artificial neural networks (ANN) are systems inspired by biological neural systems (animal brain). They are made up of a set of simple processing elements, called neurons or nodes, which are connected to each other through links which have a modifiable value called "weight".

Each neuron can receive information from other neurons (which are inputs to them) and from an external input, and it can generate output information which, in turn, can be input information for other neurons. With the information which each neuron receives, the neuron creates an output value which is a function of the linear combination of the values of its inputs, as included in Equation (1). In such equations, $y_{i}$ refers to the output value of the neuron $i, x_{j}$ is the input value of $j$ (output value of the neuron, also named with the index $j), w_{i j}$ is the weight of the connection between neurons $i$ and $j$, $\theta_{i}$ is the threshold or bias of the neuron and $f_{i}$ is the activation function. This activation function can be linear, but it is usually non-linear (sigmoidal, gaussian, etc.). This non-linearity of the activation function allows the neural network to be the universal proxy of non-linear functions. The structure of one neuron is shown in Figure 1.

$$
y_{i}=f_{i} \sum_{j=1}^{n} w_{i j} \cdot x_{j}-\theta_{i}
$$

Neural networks can be split into feed-forward networks and recursive networks, depending on how the neurons are connected. In feed-forward (or unidirectional) networks, the neurons are connected following the direction of the input to the output. The recursive networks have connections between neurons in the opposite direction.

The structure of a neural network is determined by the arrangement of the neurons, their interconnections and their activation functions. Neurons are organized in layers. Those which are not input layers (i.e., those which provide an external output) are considered as "hidden". The set of values which are presented to the neurons of the input layer (a value per neuron), which correspond to the inputs of the neural network itself, are called "value of the input vector".

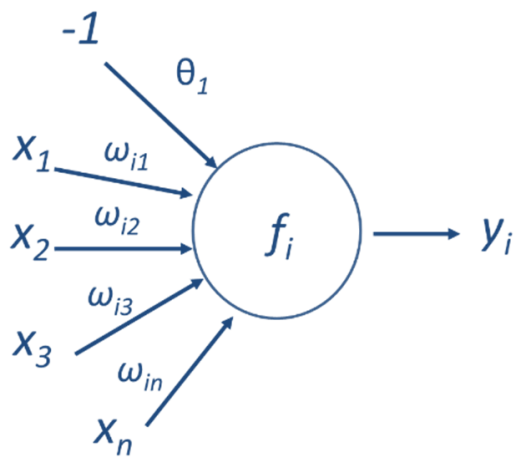

Figure 1. Processing of the information in a feed-forward neuron.

The main characteristic of neural networks is their learning capacity. This learning is the adjustment of the weights of the connections between the neurons which takes place in an interactive manner in order to achieve a desired effect. It refers to "learning" the existing relationships between pairs of values of vectors of inputs-outputs, or finding a common pattern in the input data in order to classify them according to the different patterns.

The multilayer perceptron (MLP) or neural network MLP is a type of feed-forward neural network in which the neurons are organized in layers and, thus, the inputs for a neuron located in an intermediate layer can only be the outputs of the preceding layer and its output serves as the input for the neurons of 
the following layer. Its graphical representation is provided in Figure 2, which shows two consecutive networks. In the first one, the blue neurons make up the input layer (each neuron of the input layer has an external value), the red neurons make up the intermediate layers (or "hidden" layers) and the grey neurons make up the output layer (the output value of each neuron is one of the outputs of the neural network).

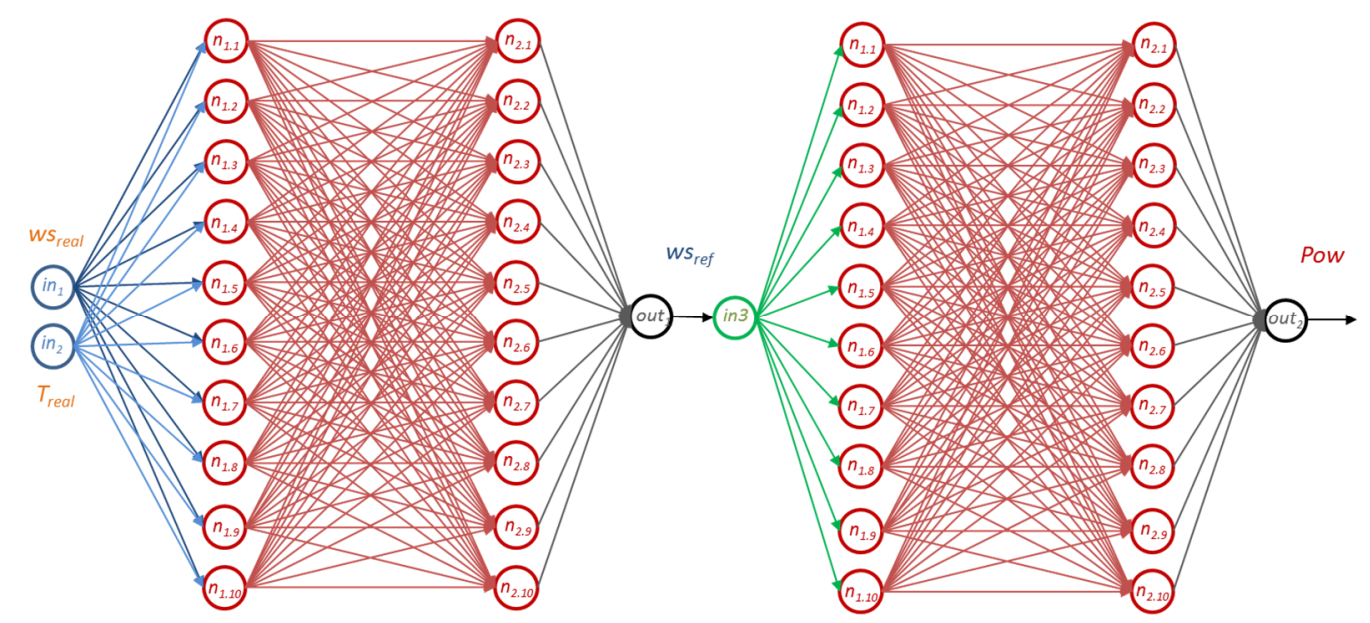

Figure 2. Illustration of both MLP ("MultiLayer Perceptron") neural networks, with the wind adjustment on the left and the power curve on the right.

An MLP neural network can have several hidden layers, although a single hidden layer could be able to approximate any continuous delimited function (whether linear or not) with a small error and two hidden layers are able to approximate any continuous function (without any error).

The design of an MLP neural network implies the selection of the number of hidden layers and the number of neurons in each layer. The greater the number of layers and neurons, the greater the capacity of the MLP neural network to adjust any function.

However, the time needed to train it (in order for the network to learn) will increase and there is a risk that the network will be overtrained. Supervised learning techniques of the neural network have been used. Previous data, which allow comparing the fitness of the model and reality, are used in those techniques. The model is adjusted depending on the estimation errors. However, a drawback of these techniques is that there is a risk that the model is over-trained. The result of over-training is that the neural network perfectly fits values that have been given to it in the input vector, giving the required value of the output vector or a very relatively close value which, however, has been "adapted" too much to those data. This leads to a loss of capacity to generalize the prediction. Any value of the input vector other than that used in the training of the neural network can provide poor results.

There are different learning and training techniques for MLP neural networks. In this study, the error back-propagation technique has been used. This technique basically consists of updating the weights of the connections between neurons in proportion to their contribution to the error. In our case, the weights of the neural network are updated after presentation of the entire set of values of the input vector of the training data (which constitutes an "epoch").

The updating of the weights of the neural network is carried out after each value of the input vector is presented. The variation in the weight of the value of the input vector $n, \Delta w_{i j}(n)$, the connection between the neurons $i$ and $j$ (neuron $i$ located in a layer posterior to the neuron $j$ ), is given by Equation (2) where $\eta$ refers to the so-called learning factor (a constant number, also called "step"), $\delta_{j}$ is the gradient of the local error of the neuron $j, o_{i}(n)$ is the output value of the neuron $i$ for the value of the input vector $n, \alpha$ is a coefficient called "moment" and $\Delta w_{i j}(n-1)$ represents the variation of the weight of the connection between neurons $i$ and $j$ for the value of the input vector $n-1$.

$$
\Delta w_{i j}(n)=\eta \delta_{j} o_{i}(n)+\alpha \Delta w_{i j}(n-1)
$$


The gradient of local error for a neuron of the output layer is the product of the derivative of the chosen error function and the activation function of the neuron. The gradient of the local error for a neuron of a hidden layer equals the weighted sum of the gradients of local errors of the neurons to which the connections from such neurons are linked (the weight of each connection acts as the weighting factor). The weighting of the connection between neurons $i$ and $j$ for the following value of the input vector $(n+1)$ is given by Equation (3).

$$
w_{i j}(n+1)=w_{i j}(n)+\Delta w_{i j}(n)
$$

In Equation (2), the coefficients $\eta$ and $\alpha$ are two constants. A high value of the learning factor $\eta$ implies that the neural network reacts quickly to changes in the inputs, but it also leads to an unstable neural network if it is very high. On the contrary, a low learning factor leads to an increase in the time needed for training the neural network.

The coefficient $\alpha$, (or "moment") describes the part of the change in the weight which is added to the next updating of the weights. A low value of the moment leads to an unstable training, it causes fluctuations in the values of the weights of the connections and hinders the learning of the neural network. The maximum value for the moment is 1 and the most usual values are between 0.5 and 0.9 .

Various techniques prevent over-fitting or over-training of the neural network, including limitation of the number of epochs in the training process (these were limited to 5000), the addition of white noise to the values of the input variables and the use of cross-checking. In the latter technique, which is the most widely used, the available data are divided into two groups: training and cross-checking $(15 \%$ in the case presented here).

The data from the training group are used in order to fit the parameters of the neural network according to the training method which has been chosen. The data from the cross-checking group are not used in determining the error which has to be minimized with the training of the neural network, but instead are presented to the neural network after each training epoch. The training process is interrupted when a given number of epochs have gone through without a reduction in the error from the cross-checking data.

\subsubsection{Fuzzy Logic}

The Fuzzy logic is a technique which aims to include the structured human knowledge in efficient algorithms. Many human intellectual processes are based on inductive reasoning. A clear example is the reasoning which leads to logical structures such as "IF ... THEN". We can thus argue that human knowledge is structured in rules such as "IF ... THEN", and that this combination of rules leads to actions and decisions. A rule of this type is a function of multiple variables which relates the variables associated to "IF" and named "antecedents" or "causes" to the variables associated to "THEN", which are named consequences or effects.

One of the features of human knowledge is that it characterizes situations, elements, properties, etc., in a fuzzy or vague manner. However, there is an inherent uncertainty in this idea: which is the frontier between a high and a normal ambient temperature? This uncertainty can be delimited in mathematical terms through a so-called membership function. This is the mathematical equation of degree between 0 and 1 which values the membership of an element to a given set defined by a specific fuzzy term (in this case "very high").

A fuzzy universe can be one which applies to different zones of the power curve of the wind turbines defined in Section 2.2. Fuzzy sets can be applied, for example, to zones of start-up, rise and nominal capacity of the equipment, as a function of the control strategy of the manufacturer, as shown in Figure 3. 


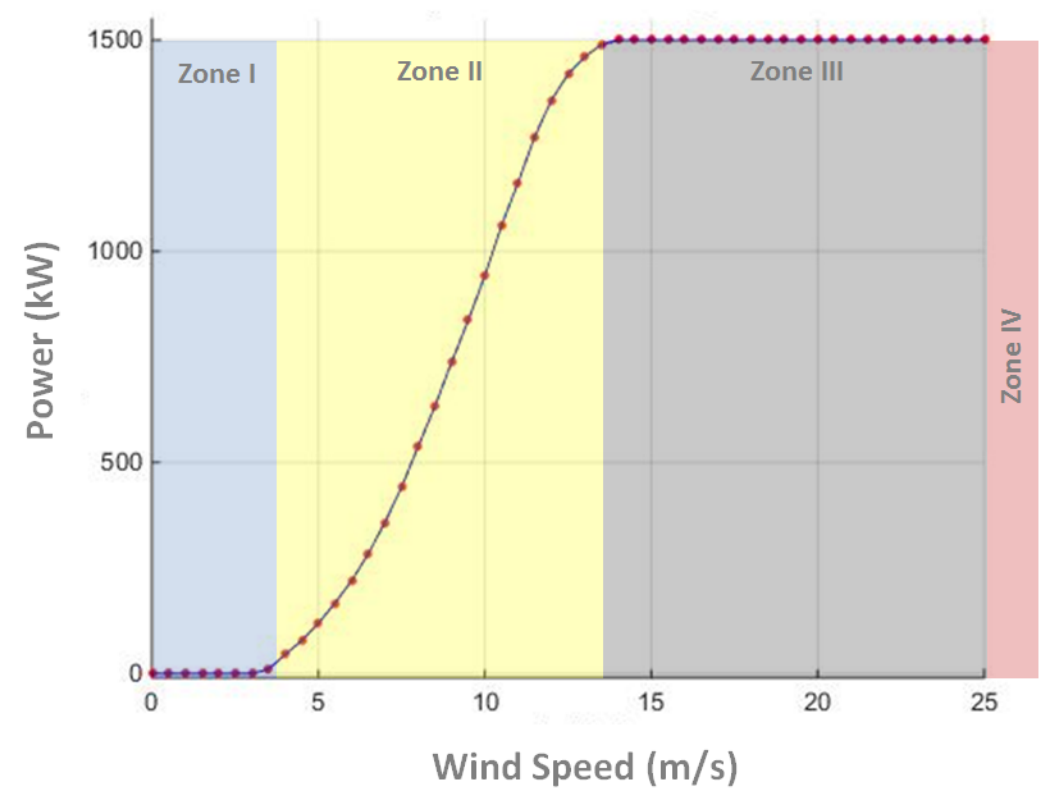

Figure 3. Wind turbine power curve (Pow-ws) for reference air conditions (with $T_{r e f}=25^{\circ} \mathrm{C}$ and $P_{\text {ref }}=1001$ bar $)$.

A fuzzy set is represented by a label (for instance, $Z$ ), which takes values within the universe $X$. This is characterized through a membership function $\mu_{z}$, which takes values between 0 and 1 . The mathematical equation for a fuzzy set is reflected in Equations (4) and (5).

$$
\begin{gathered}
A=\left\{\left(x, \mu_{Z}(x)\right) \mid x \in X\right\} \\
\mu_{Z}: X \rightarrow[0,1]
\end{gathered}
$$

The membership function is a function which links each element of the fuzzy set to a value within the interval $(0,1)$ and within the universe. The most usual membership functions are: triangular, trapezoidal, Gaussian, sigmoidal and normal.

\subsection{Wind Turbine Power Curve and Performance Dependency with Environmental Temperature}

Horizontal axis wind turbines generate energy based on the power curve of Figure 3. As is shown, the power depends on the wind speed (for a reference air density). The energy generated by a wind turbine will therefore be the integral of the instant power $(P(t))$ in a given period $\left(\left[t_{0}, t_{1}\right]\right)$, according to Equation (6). Currently, the dominant method to calculate the energy produced by wind farms is based on the use of this static curve.

$$
E_{t 0}^{t 1}=\int_{t 0}^{t 1} P(t) \cdot d t
$$

The power curve can be divided into four different zones according to the control strategy [20], which will affect the behavior of the pitch control and, thus, the exposure of the surface of the blades to airflow changes. In Zone I, the wind turbine stops due to the fact that there is not enough wind to move the hub. Zone II represents the acceleration slope, in which the blades expose their entire surface to capture as much energy as possible from the air. When the wind turbine reaches its nominal power, represented in Zone III, the control system changes the pitch in order to keep the energy captured from the air constant. Finally, in zone IV, the wind speed is too high to operate the wind turbine in safety conditions and it is stopped.

This power curve depends on the air density at each moment. For that reason, the wind turbine manufacturer provides power curves for different air density scenarios. According to Betz's Theory, 
the ideal relationship between the wind speed and the power generated by the wind turbines can be defined by Equation (7) [7,18,20]:

$$
\text { Pow }=C p \cdot \frac{1}{2} \cdot \rho \cdot A \cdot w s^{3}
$$

where $C p$ is the power coefficient, $\rho$ is the air density, $A$ represents the whipped area of the blades and ws is the wind speed.

There is a relation between air density and external temperature and, consequently, the production model should automatically change according to this effect. In this article, a production model that characterizes this power curve for a specific wind turbine technology [14] has been developed, but the wind speed as well as the external temperature have been included as inputs to the model. We illustrate this methodology with different production scenarios, considering different levels of increase in the environmental mean temperature. The power curve is provided by equipment manufacturers for a given air density, since, depending on such density at a given moment, wind will transport more or less energy (for a given wind speed) [17]. Since density is equal to the mass divided by the volume, air density affects mass per unit of volume. Thus, the greater the mass (per unit of volume) is, the greater its energy for a given wind speed will be. This effect is shown in Figure 4.

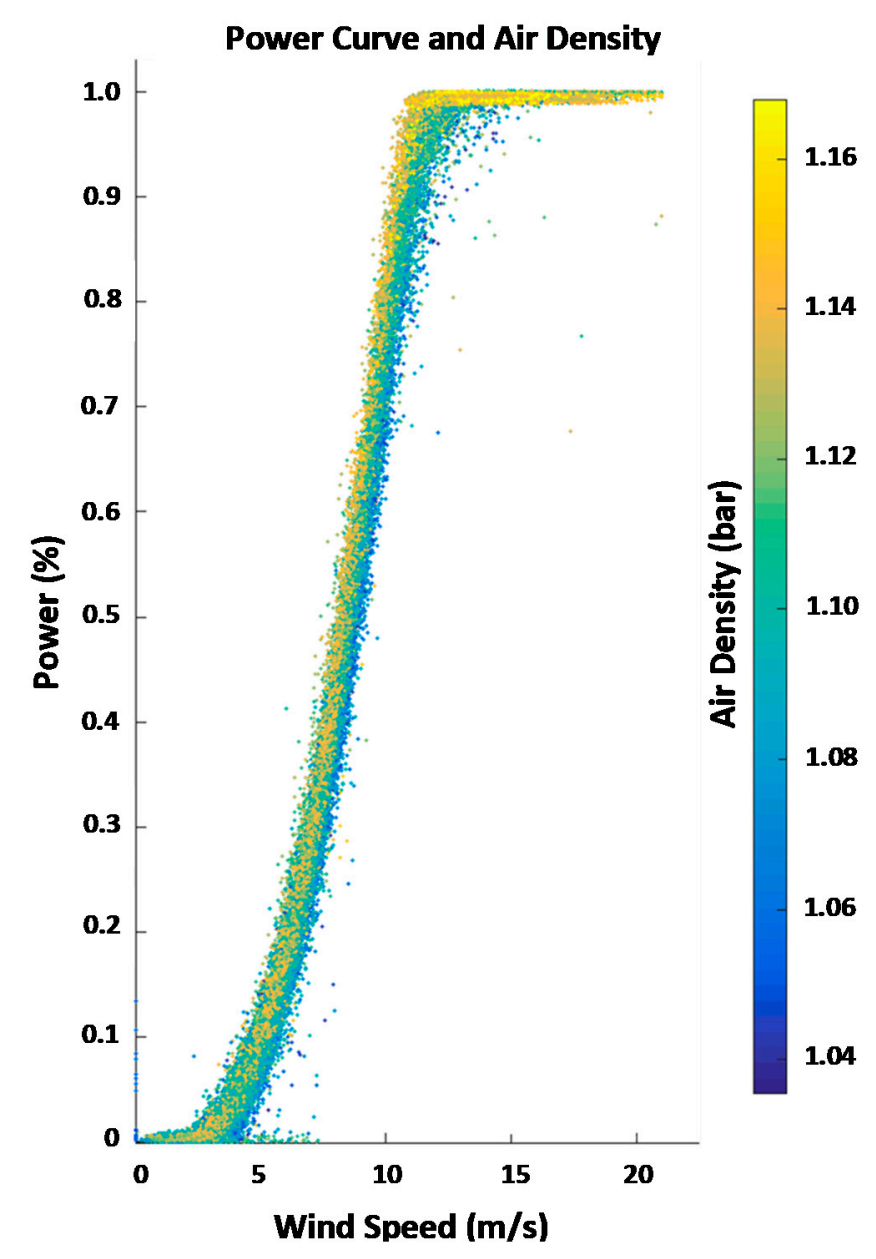

Figure 4. Wind turbine power curves (Pow-ws) for different air densities (in the color scale).

Figure 4 represents the normalized power (Pow) generated as a function of wind speed measured at the rotor hub (ws). The figure shows the power curves of a wind turbine of the wind farm analyzed in this article at different moments during the year. The color indicates air density in each moment. In the inner part of the figure, a greater concentration of blue points (low air density) can be observed, whereas there is a concentration of yellow points (greater air density) in the outer layer of the figure. 
When the air density is higher, the power curve shifts to the left. With a lower wind speed (but higher air density), more energy is produced. Therefore, with a lower air density, the turbine needs a higher wind speed in order to generate the same amount of electricity. A higher air density entails more particles (mass) in the same volume of air. All these particles have kinetic energy that can be captured by the blades. Temperature increases reduce the number of particles in the same volume of air. For that reason, the energy of a volume of wind in movement is lower. Using Equation (7) and the Ideal Gas Law Equations (8)-(12), the wind speed measured $\left(w s_{\text {real }}\right)$ can be adjusted to the effective or reference wind speed $\left(w s_{r e f}\right)$ through two physical variables: atmospheric pressure $(P)$ and temperature $(T)$ measured at the site. As suggested by Equation (13), a higher $T_{\text {real }}$ (measured at the site) leads to a lower effective speed.

$$
\begin{gathered}
P \cdot V=n \cdot R \cdot T \\
P \cdot V=\frac{m}{M} \cdot R \cdot T \\
P \cdot M=\frac{m}{V} \cdot R \cdot T \\
\frac{P \cdot M}{R \cdot T}=\frac{m}{V} \\
\rho=\frac{P \cdot M}{R \cdot T}
\end{gathered}
$$

It can also be observed that, according to Equation (7), the theoretical power depends on the air density $(\rho)$ which, in turn, depends on other factors such as temperature. The parameter $(R)$ is the constant of ideal gases. We can use the ideal gas law (Equation (8)) and perform some stoichiometric calculations of the density of a gas (Equation (12)). This equation shows how the density of the gas depends on temperature. The number of moles is equal to $m / M$, where $m$ is the present mass, $M$ refers to the molecular mass of the gas and the density is $m / V$. From Equation (7) it is possible to obtain Equation (13) by considering two different environmental scenarios and matching the energy produced.

$$
w s_{\text {ref }}=w s_{\text {real }} \cdot \sqrt[3]{\frac{P_{\text {real }} \cdot T_{\text {ref }}}{P_{\text {ref }} \cdot T_{\text {real }}}}
$$

The reference values $\left(w s_{r e f}, T_{\text {ref }}\right.$ and $\left.P_{\text {ref }}\right)$ are the parameters that feature the conditions of operation of the equipment (determined by the manufacturer). The power curves used by the SCADA (Supervisory Control And Data Acquisition system) of operation are fixed for predefined (or reference) conditions (based on the fact that the operation of the equipment is regulated).

The methodology developed in this paper is based on the fact that the neural network itself is able to transform the values measured in the wind turbine $\left(w s_{\text {real }}\right)$ at an effective wind speed $\left(w s_{r e f}\right)$, only considering the variable ambient temperature $\left(T_{\text {real }}\right)$. Therefore, the neuronal network will be able to reproduce the hidden nonlinearity in the relationship $\left(P_{\text {real }} / P_{\text {ref }}\right)$. It is necessary to follow this approach, since, although the average thermal increase is known, it is unknown how climate change will affect the barometric pressure of the sites $(P)$.

\subsection{Wind Turbine Power Curve Model}

This section describes the methodology developed to assess the performance losses based on the wind turbine power curve [20].

\subsubsection{Data Pre-Processing}

The data used for the development of the models come from 20 wind turbines located in Spain, with 1.5 MW of unit power for a period of 4 years (approximately 4,204,800 ten-minute time records). The first years of operation of the 20 wind turbines were considered for building up the model (2008 and 2009) and the data of the following two years (2010 and 2011) were used to calculate the errors of the 
model. The production history of the wind farm, which is used to perform simulations of the loss of performance, corresponds to the entire period of 4 years (2008-2011).

Based on the expert assessment and preliminary studies, the variables of the wind turbines considered for building the energy production model of the wind turbines were:

- $\quad$ Air Temperature $\left[{ }^{\circ} \mathrm{C}\right]$.

- Barometric Pressure [bar].

- Wind speed $[\mathrm{m} / \mathrm{s}]$.

- $\quad$ Power $[\mathrm{kW}]$.

Once the variables are selected, outliers in the samples need to be identified. These outliers can be physically impossible temperatures (due to failures in measurement equipment) or non-typical data due to abnormal operation condition of the turbine [14]. The data processing consists of two stages: filtering (manual/statistical filter) and data normalization. For each of the variables under consideration, this filter only eliminates values that do not make any sense taking into account the logical perspective of operation $[25,26]$. These values are possibly due to faults in the sensorics or a result of a clearly anomalous operation. Given that no limits of the operating variables were known, a statistical study was undertaken through an assessment of distribution parameters (mean and standard deviation). Based on the values obtained, the operating limits (lowest and highest) were obtained for each variable based on an expert judgment.

The applied manual/statistical filter has been:

- $\quad-10<T\left({ }^{\circ} \mathrm{C}\right)<50$

- $\quad \leq w s(\mathrm{~m} / \mathrm{s}) \leq 13$ (when modeling zone 2)

- $\quad<P($ bar $)<1050$

- $\quad 0<$ Pow (\% of rated power) $<96 \%(1450 \mathrm{~kW})$ (when modeling zone 2$)$

- $\quad w s(\mathrm{~m} / \mathrm{s}) \geq 5 \&$ Pow (\% of rated power) $<2.5$ (If the wind speed is higher than $5 \mathrm{~m} / \mathrm{s}$ but the Pow is lower than 2.5, the turbine is damaged or stopped and, thus, the corresponding data should be removed.)

- $w_{s}(\mathrm{~m} / \mathrm{s})<4 \&$ Pow (\% of rated power) $>7.5$ (Likewise, if the wind speed is lower than $4 \mathrm{~m} / \mathrm{s}$ but the Pow is higher than 7.5 , the anemometer is either damaged or broken. Therefore, the corresponding data should be removed.)

- The equipment is available during the $10-\mathrm{min}$ period of the data.

Because the models are built with input variables from different units and scales, the data have to be normalized in order to be able to compare the fluctuation scale of different variables and to ensure that more weight is not given to a variable with higher figures. The variables were normalized according the Equation (14):

$$
i_{t \text { Normalized }}=\frac{i_{t}-i_{\text {min }}}{i_{\max }-i_{\text {min }}}
$$

where $i_{t}$ is the value recorded by one of the variables at time $t, i_{\min }$ is the minimum value of each variable in the entire population set and $i_{\max }$ refers to the maximum value of each variable in the entire population set. The entire data set, including simulation data, is considered.

However, the $i_{\max }$ value must be corrected, taking into account the ambient temperature variable. This variable is increased manually in simulations with values up to $6{ }^{\circ} \mathrm{C}$ higher than those registered. Therefore, the neural network model must be prepared for this if the aim is to correctly simulate those temperatures. This is achieved by changing $i_{\max S}=i_{\max }+6{ }^{\circ} \mathrm{C}$.

During the process of the standardization of variables, the statistical parameters of each variable should be saved, due to the fact that the data which is subsequently used as input in the model for global warming simulations should be normalized based on these parameters. Therefore, the global warming simulation temperature data set must be normalized with $i_{\min }$ and $i_{\max S}$ of the training data set in order for the model to be applicable. 
The model of electricity production based on neural networks applies only to the zone of the ramp of the power curve because, for wind speeds higher than $13 \mathrm{~m} / \mathrm{s}$ and lower than $25 \mathrm{~m} / \mathrm{s}$, the power delivered by the equipment will be the nominal one. This is because the adjustment of the pitch will allow capturing more energy from wind in order to maintain the torque (or the revolutions of the generator).

\subsubsection{Power Curve Modeling Methodology}

Currently, the dominant method to calculate the energy that can be produced by wind farms is the Power-Speed curve of wind at a given site (Figure 3). The drawback is that this curve is fixed for a given air density and the power which can potentially be produced is estimated only as a function of the wind at a given moment. However, as shown above, the actual power being produced is not only dependent on the wind but also on air density.

Therefore, there should be a different power curve for each air density or a non-linear model which considers the electricity which can be produced as a function of wind and density (or alternatively, as a function of other representative variables such as temperature and humidity). There is a wide array of mathematical and statistical techniques which can be used to calculate the power curve of a wind turbine $[27,28]$. However, the difficulty of building an analytical model based on equations which simultaneously include the impact of the aforementioned factors led us to use "black box" modeling methods and, particularly, ANN [14,29,30].

The model is an expert system made up of a module of Fuzzy logic rules and three submodels. The module of Fuzzy logic rules is responsible for the selection of the submodel which applies at each moment. It identifies the operation zone of the power curve (Figure 3) where the wind turbine is at each moment $(t)$.

The power curve can be divided into four (4) different regions:

1. Zone (1), where the wind energy is insufficient to start-up the wind turbine movement. In that case, the expert system would apply the model Pow $=0$.

2. Zone (2) is called the ascending ramp, where the wind turbine is accelerated until its nominal rotation speed rises. In that case, the expert system will apply the neural network model later described.

3. Zone (3), where the wind turbine rises to nominal power. In that case, the expert system will apply the model Pow $=$ Pow $w_{\text {nominal }}$.

4. Zone (4), where the wind energy is excessive to operate under safe structural conditions. In that case, the expert system will apply the model Pow $=0$.

Figure 5 shows four membership functions for the four Fuzzy sets defined for the universe in the interval $(0,30)$. The four membership functions are trapezoidal and represent the different strategies for the operation of a wind turbine.

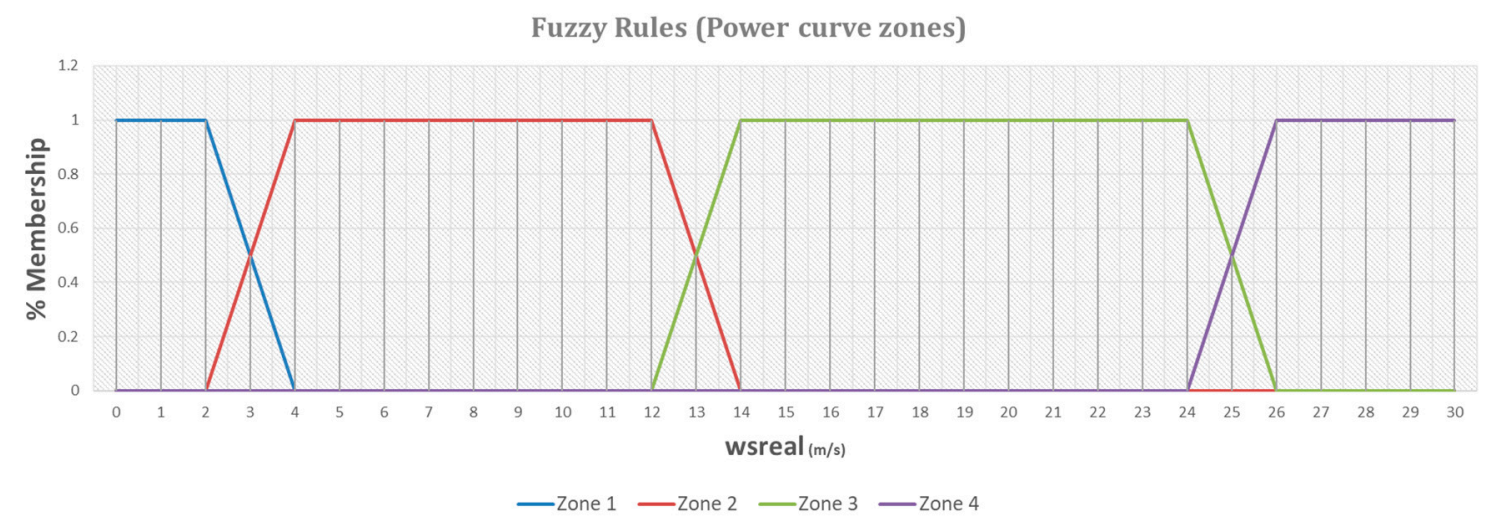

Figure 5. Fuzzy logic rules to classify the operational state. 
For each operational zone, a model was built. The Fuzzy logic rules system identifies which model should be used at each moment. According to these rules (Figure 5), data will be marked every ten minutes with the number of the zone they belong to. The transition between zone 1 and 2 is effective when $w s_{\text {real }}(t) \geq 3 \mathrm{~m} / \mathrm{s}$. The transition between zones 2 and 3 is effective when $w s_{\text {real }}(t) \geq 13 \mathrm{~m} / \mathrm{s}$. Finally, the transition between zones 3 and 4 is effective when $w s_{\text {real }}(t)>25 \mathrm{~m} / \mathrm{s}$.

As it was shown in Figure 4, the air density mainly affects the zone 2, which corresponds to the acceleration ramp. For that reason, it has been assumed that global warming will not affect the performance of the wind turbine when it works in zones 1,3 or 4 .

Figure 6 represents the expert system that activates the model which applies in each moment according to $w s_{\text {real }}$. The model for zone 2 (red line in Figure 5) is made up of two neural networks (Figure 2). One of them adjusts the wind speed $w s_{\text {real }}$ to $w s_{\text {ref }}$ (with $T_{r e f}=25^{\circ} \mathrm{C}$ and $P_{\text {ref }}=1001 \mathrm{bar}$ ), whereas the other network estimates the power that can be produced from $w s_{r e f}$. This second neural network could be replaced by the power curve of the manufacturer for the given reference conditions. However, we have decided to calculate the real curve for the wind turbines of the wind farm since, as mentioned in the literature $[14,27,28]$, each wind turbine has a specific curve as a function of many determining factors, including its location, presence of nearby wind turbines and configuration parameters.

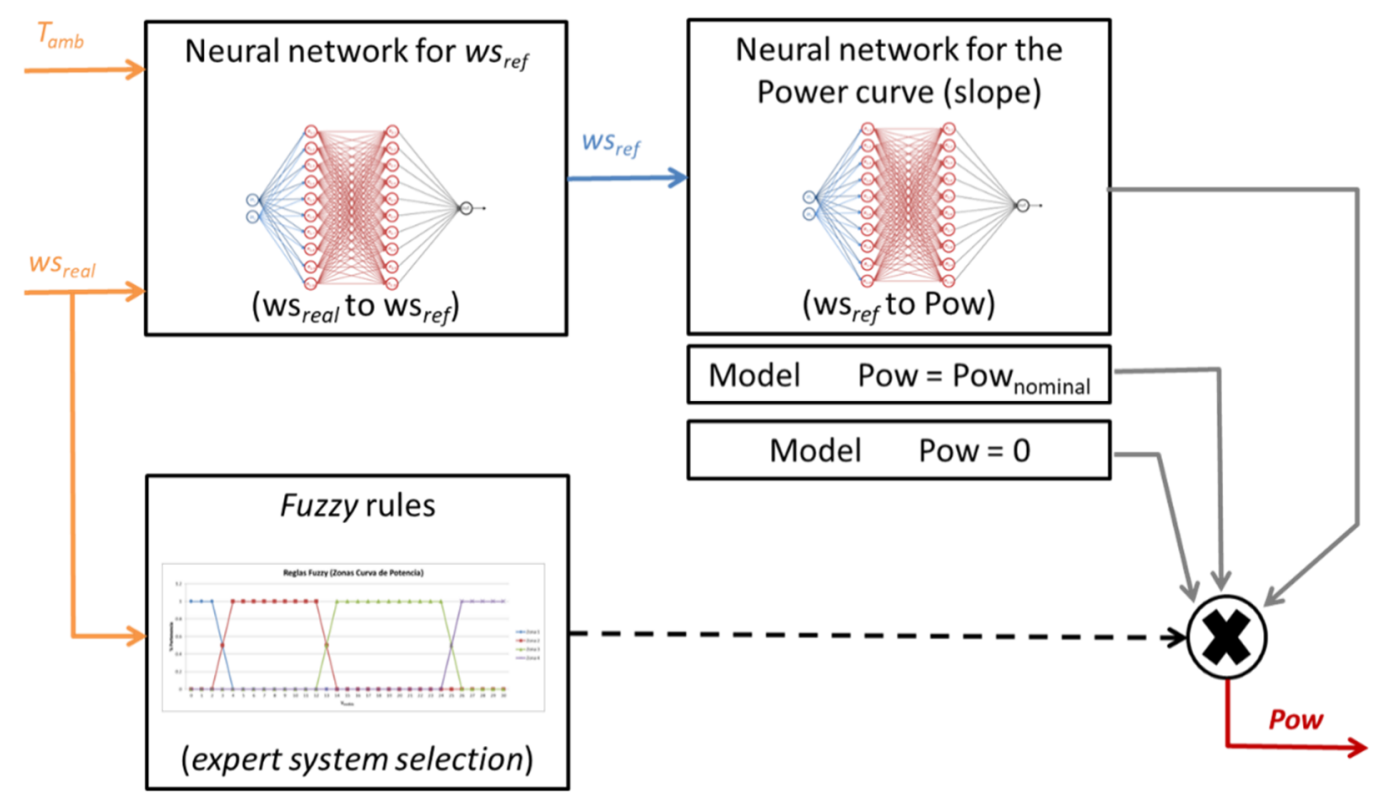

Figure 6. Conceptual scheme of the expert system with the Fuzzy logic rules and two neural networks models used for the characterization of the energy that can potentially be produced in the zone corresponding to the ramp.

Therefore, two neural networks of the MLP type were used in order to build the production model which includes global warming variables. This is a type of neural network in which the neurons are organized in layers, so that the input of a neuron located in an intermediary layer can only be the output of the preceding layer, while its output serves as the input for neurons in the next layer. This is shown in the graph in Figure 2, where the input layer is formed by the aforementioned operating variables, two inputs for the first net in blue ( $w s_{\text {real }}$ and $\left.T_{\text {real-simulated }}\right)$, and the corrected wind speed $\left(w s_{\text {ref }}\right)$ for the second net in green. After the input layer, there are neurons named intermediary or hidden layer. A structure of two hidden layers [14] with ten neurons (n) per layer was used in the development of both neural nets $\left(n_{1 . x}\right.$ for the first layer and $n_{2 . x}$ for the second one, where $\left.x \in\{1, \ldots, 10\}\right)$. Finally, the nets present the neurons forming the output layer in gray, the output values are the $w s_{r e f}$ in the first net (out ${ }_{1}$ in Figure 2) and the energy production (Pow) for the second one (out $t_{2}$ in Figure 2) during the interval of time. 
As mentioned above, the first neural network replaces Equation (13) that relates $w s_{\text {real }}$ with $w s_{\text {ref }}$ based on barometric pressure and ambient temperature. Therefore, it is necessary to have the operating data of the first two years for several variables in order to train this neuronal network: wind speed $\left(w s_{\text {real }}\right)$, measured barometric pressure $\left(P_{\text {real }}\right)$ and measured temperature $\left(T_{\text {real }}\right)$. Equation (13) is applied and the reference wind speed $\left(w s_{r e f}\right)$ has been calculated for this data set. Using this procedure, the neural network can be trained, considering $w s_{\text {real }}$ and $T_{\text {real }}$ as inputs and the objective variable $w s_{\text {ref. }}$. Thanks to this training, the $w s_{\text {ref }}$ can later be estimated considering only $w s_{\text {real }}$ and $T_{\text {real }}$ as inputs. This will allow us to carry out simulations in which $T_{\text {real }}$ is changed according to the temperature increases due to the effects of global warming $\left(T_{\text {realGW }}\right)$.

\section{Results}

\subsection{Estimating Wind Production with the Model}

The model of wind energy generation, which takes into account wind speeds and the temperatures at the site, has been estimated and increases in temperatures have been simulated.

In order to visually verify the goodness of fit of the model, Figure 7 shows the real production of the wind turbine (in blue) and the production estimated by the model (in grey) for a short period of time as an example.

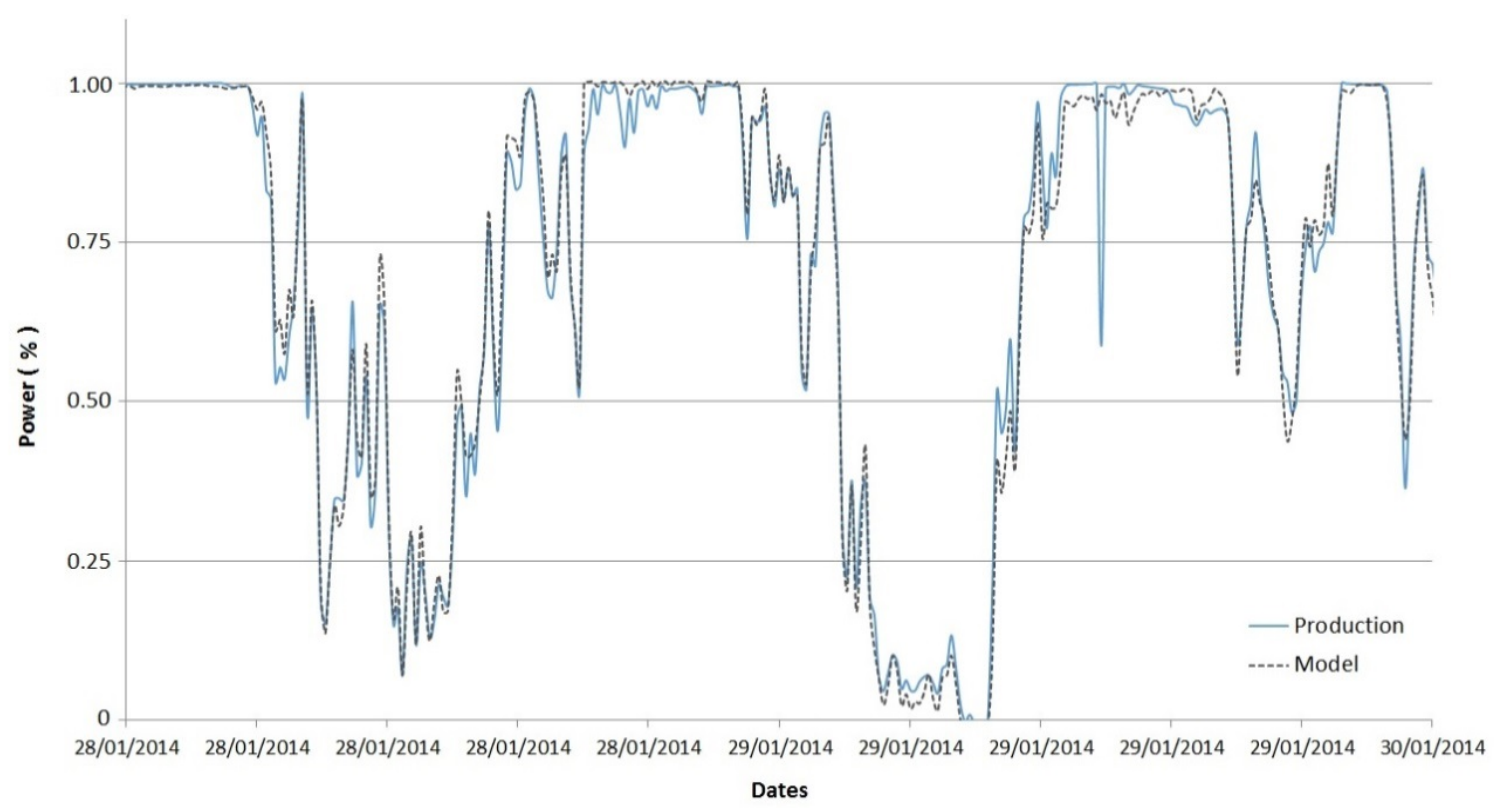

Figure 7. Illustrating the difference between real and estimated production (the continuous line refers to the real normalized production of a wind turbine and the dotted line represents the estimated production).

The goodness of fit of the model (zone 2) is very good $\left(R^{2}=0.9935\right.$ in Figure 8$)$, since it is a wind farm or a technology-level model. A single model of producible energy at the wind farm level was built. In total, 283,681 10-min records of zone 2 were available for the 20 wind turbines in the farm. Since the first 2 years of operation of the 20 wind turbines were used for model training, a total of 2,102,400 records were used for training and another 2,102,400 different records were used for the validation. It should be taken into account that a large number of these records had "null" data due to the filtering criteria. The average percentage error obtained with the validation data set was $-0.39 \%$ and the average error was $-8.69 \mathrm{~kW}$. The average percentage error of the whole expert system, considering zones 1 to 4 , was $-0.23 \%$ (see the joint response of the models in Figure 9). 


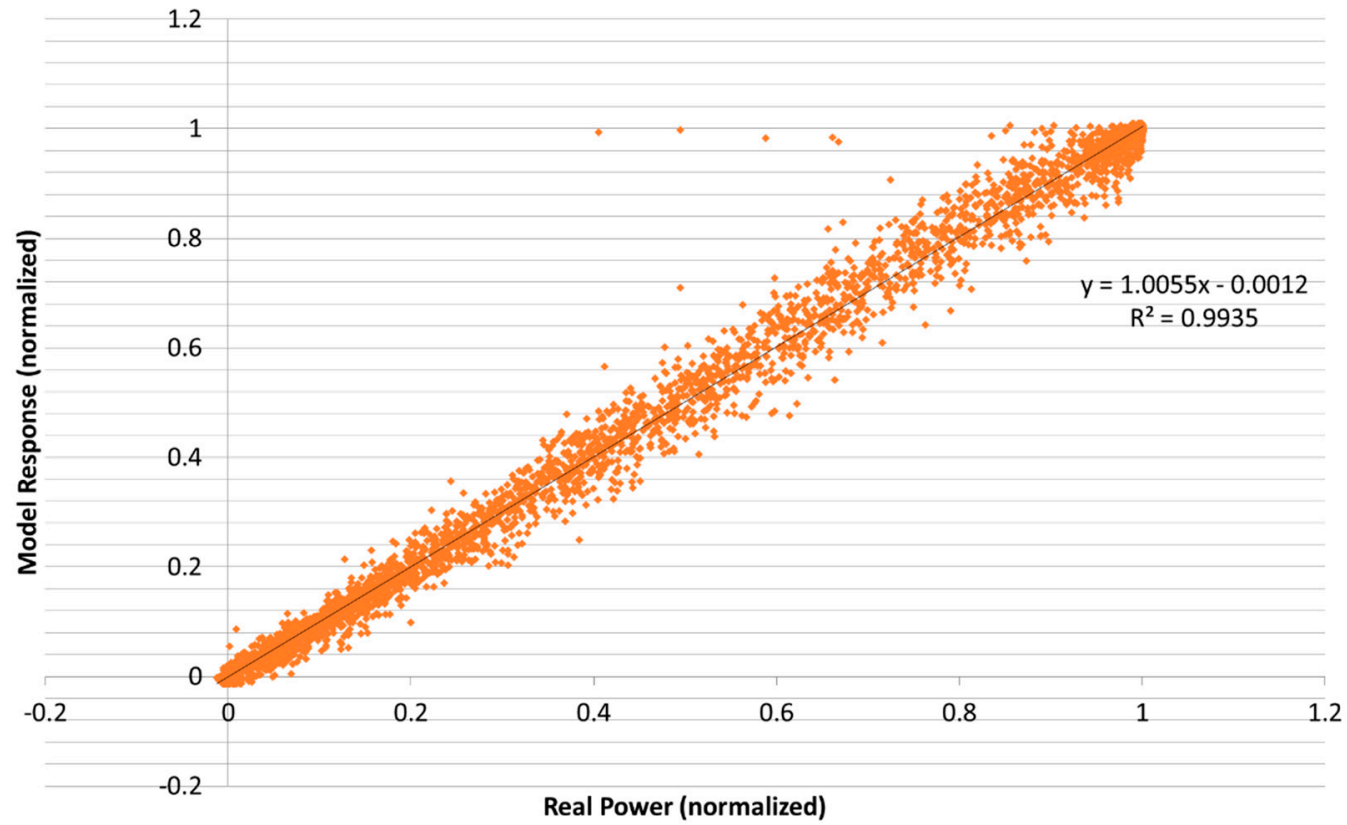

Figure 8. Regression line between the normalized real power ( $x$-axis) and power estimated by the wind energy model (y-axis).

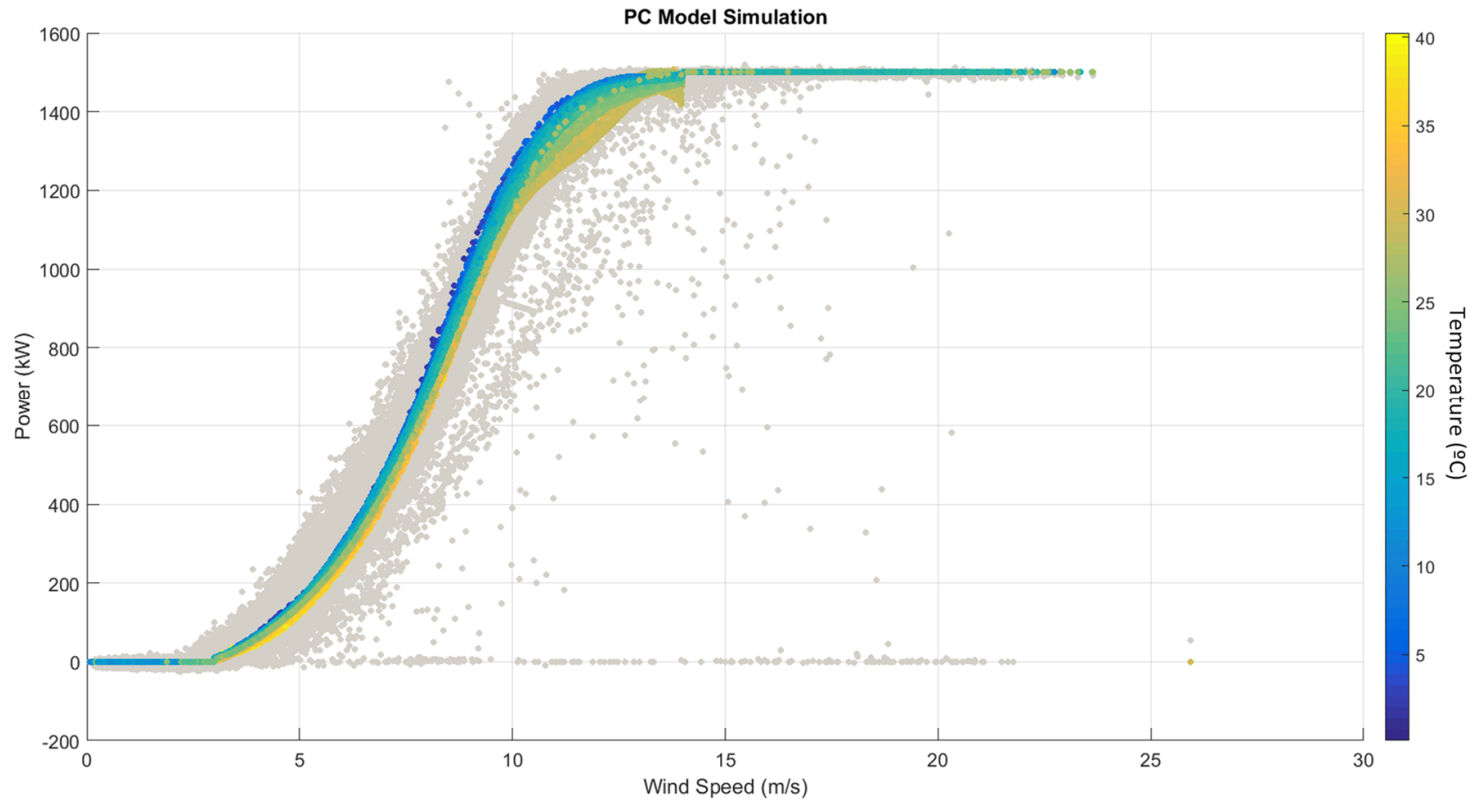

Figure 9. Power curve of a wind turbine. Real sample data vs. fitted model for reference parameters.

Figure 9 shows the power curve for different environmental conditions. The $x$-axis refers to wind speed $\left(w s_{\text {real }}\right.$ in $\left.\mathrm{m} / \mathrm{s}\right)$, whereas the $y$-axis represents wind energy generation (Pow) for different temperature values (shown in color). The degradation due to climate change will only affect the ramp-up part of the curve $\left(w s_{\text {real }} \geq 4 \mathrm{~m} / \mathrm{s}\right.$ and $\left.w s_{\text {real }} \leq 13 \mathrm{~m} / \mathrm{s}\right)$. In the upper part $\left(w s_{\text {real }}>13 \mathrm{~m} / \mathrm{s}\right)$, the wind turbine reaches the nominal revolutions, and these are maintained by adjusting the angle of the blades. As a result, the wind turbine is able to capture more energy. This will mitigate the losses due to climate change, i.e., they will not be as high as expected. The plotted model shows the relevant impact of external temperature, mainly in the zone close to nominal power, where the control system starts the adjustment of the blades' pitch. It can be observed that days with higher temperatures move the curve to the right. 


\subsection{An Application of the Methodology}

This section illustrates the methodology with a calculation of the loss of performance of the wind turbines under different warming conditions (e.g., for each additional degree of global warming). It has been shown that the thermal increase would affect the ramp-up part of the curve. As can be observed in Figure 10, neural networks estimate a power curve for the turbines depending on the temperature $\left(w s_{\text {real }}-P o w\right)$. Using this model, different global warming scenarios were simulated by gradually increasing the temperature at the site. In other words, if the temperature registered was $30^{\circ} \mathrm{C}$, one additional degree of global warming would have increased the temperature to $31.5^{\circ} \mathrm{C}$ in the 2DS scenario (since, currently, warming is around $0.5^{\circ} \mathrm{C}$ [31]).

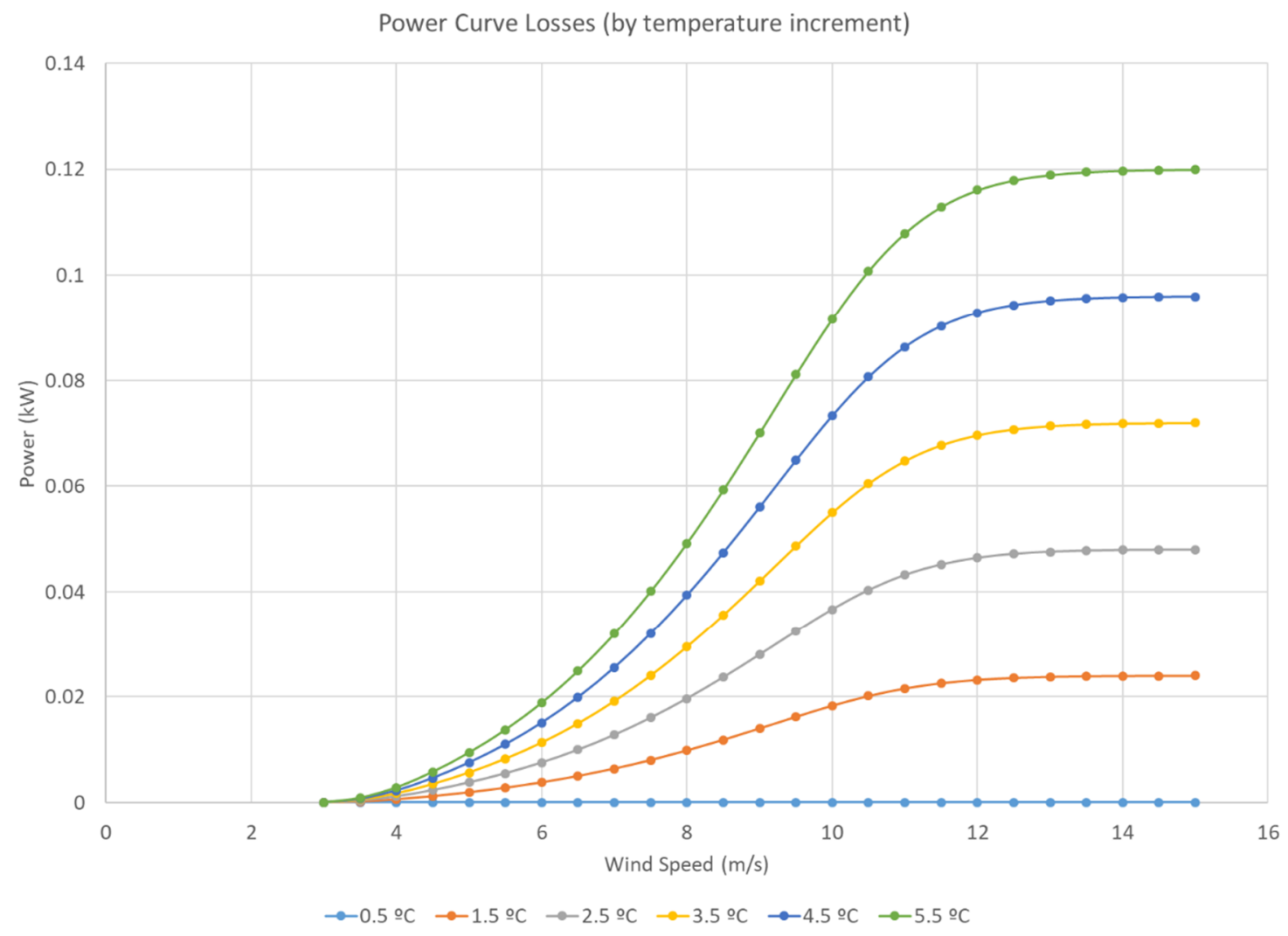

Figure 10. Losses in the power curves for the different global warming scenarios. Temperature increases from the current reference situation are considered. Power represents the losses from the reference scenario $\left(0.5^{\circ} \mathrm{C}\right)$.

The historical data of the wind farm used in this article refer to the period 2008-2011. According to [30], the global warming experienced in this period was above $0.5^{\circ} \mathrm{C}$. Departing from this starting point, we have analyzed scenarios with higher global warming (at $0.5^{\circ} \mathrm{C}$ intervals, from $0.5^{\circ} \mathrm{C}$ to $6^{\circ} \mathrm{C}$ ).

In order to simulate the possible impact of global warming on the wind farm's electricity production, it has been assumed that wind conditions (direction, frequency and intensity) are constant and that only average temperatures (and, thus, density) change [21-23]. Under these premises, the production of the wind farm has been simulated (as a sum of the individual production of each turbine) using the available historical data and increasing the average temperature.

Since there is an intrinsic error between the model and the real production of the turbine, the performance loss will be calculated with respect to the production estimated by the model under current temperature conditions $\left(0.5^{\circ} \mathrm{C}\right)$ and not with respect to the current production. A performance indicator was created, from which the percentage loss of installed power based on temperature was 
obtained (Figure 11). By way of example, the wind farm performance in a scenario of a global warming of around $6{ }^{\circ} \mathrm{C}$ is calculated as Performance $(\%)_{6}{ }^{\circ} \mathrm{C}=100$ Production $_{6}{ }^{\circ} \mathrm{C}$ Production $_{0.5}{ }^{\circ} \mathrm{C}$.

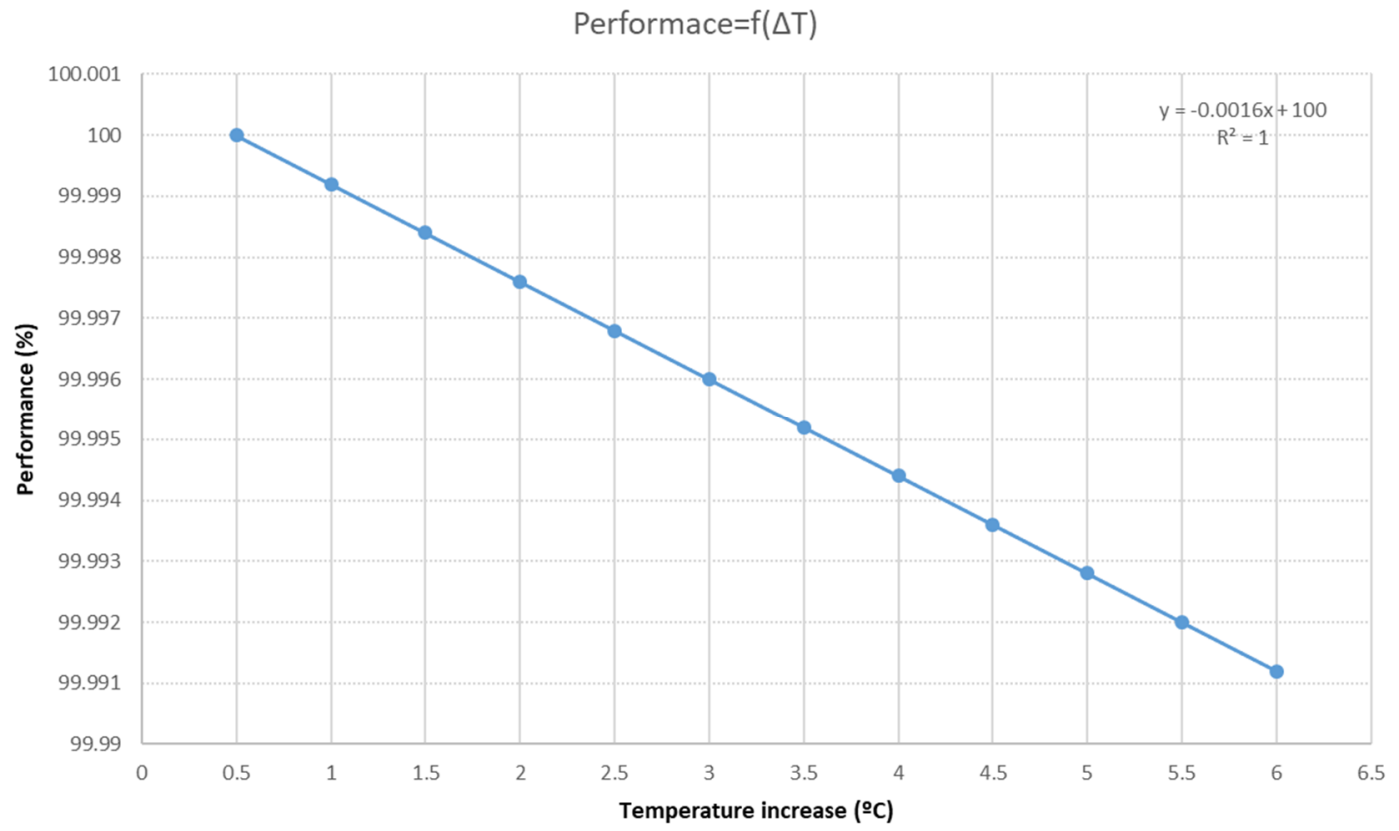

Figure 11. Continuous performance losses as a function of external temperature increases for the considered scenarios.

Since global warming will gradually increase over time, the loss of performance will not start immediately, but will also be gradual from 2015 to 2050. Therefore, a continuous function which relates the loss of performance and the thermal increase due to global warming has been used $\left(\eta=f\left(\Delta T_{G W}\right)\right.$ ). The adjustment shown in Figure 11 and its adjustment function is represented by Equation (15). This equation of the thermal increase (and, thus, the progressive degradation of the performance) is used in order to calculate the energy which has been lost during the period. It was obtained through an assessment of the trend curve that best fitted the discrete values of the performance losses of the different simulations.

$$
\text { Performace }=100-0.0016 \cdot\left(\Delta T-t_{0}\right)
$$

where $\Delta T$ represents the increase in temperature due to global warming. The offset $t_{0}$ corresponds to the current warming of $0.5^{\circ} \mathrm{C}$.

The environmental thermal increase has been simulated according to Equations (16) and (17). Figure 12 shows the thermal increase in the 2015-2050 period in the different scenarios: Current scenario $\left(0.5^{\circ} \mathrm{C}\right), 2 \mathrm{DS}$ scenario $\left(2{ }^{\circ} \mathrm{C}\right)$ and Current Policies scenario $\left(6^{\circ} \mathrm{C}\right)$. This last scenario would be the one projected until 2050 by the IEA if current energy policies continue to be implemented [5], and the generation mix is similar to the one that we have today.

The curves for the thermal increase have been built according to Equations (16) and (17):

$$
\begin{aligned}
& \Delta T_{x}=t_{0} \cdot a^{x} \\
& a=\sqrt[35]{\frac{t_{f}}{t_{0}}}
\end{aligned}
$$

where $\Delta T_{x}$ represents the thermal increase ( $y$-axis), $t_{0}$ is the initial temperature $\left(0.5^{\circ} \mathrm{C}\right.$ for 2015$), t_{f}$ is the maximum admissible temperature for 2050 (in the 2DS), 35 is the number of intervals from 2015 to 2050 and $x$ is the number of intervals for which we would like to know the warming (for 2030, $x=15$ ). 


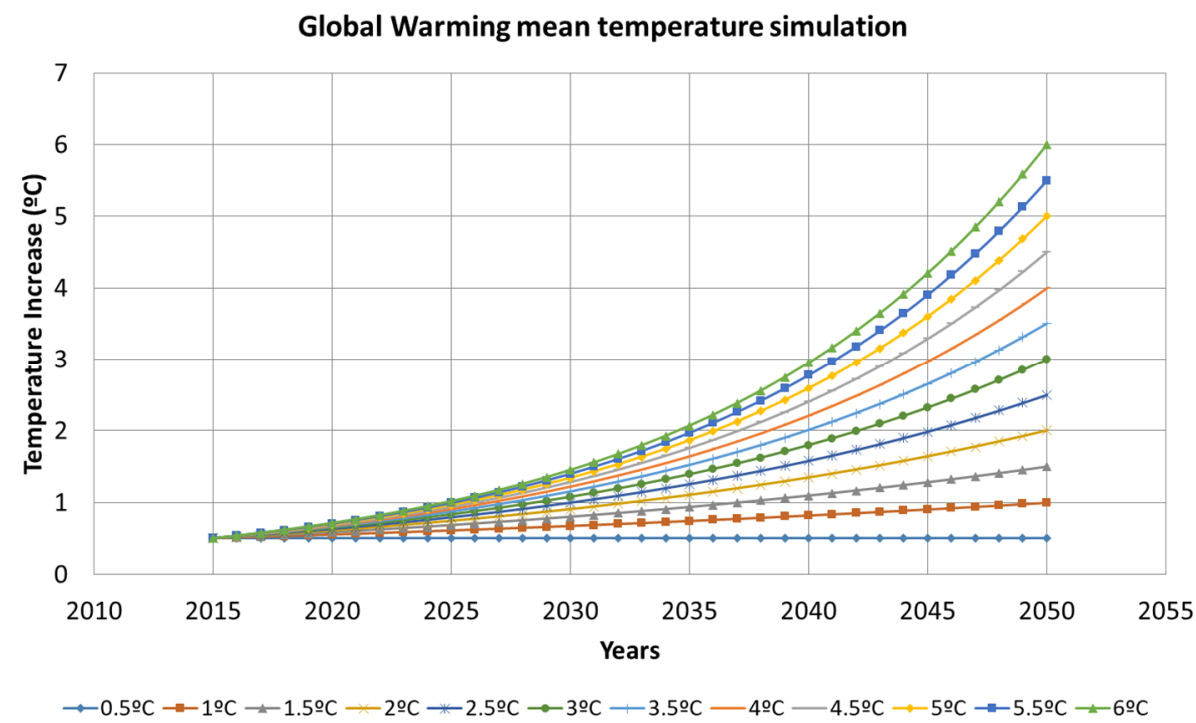

Figure 12. Mean temperature for the different scenarios.

The joint equation obtained after merging Equations (15)-(17) allows us to directly calculate the performance loss over time according to the expected evolution (Equation (18)). These equations have been jointly represented in Figure 13.

$$
\text { Performace }_{i}=100-0.0016 \cdot t_{0} \cdot\left(\left(\sqrt[35]{\frac{t_{f}}{t_{0}}}\right)^{\text {year }_{i}-\text { year }_{0}}-1\right)
$$

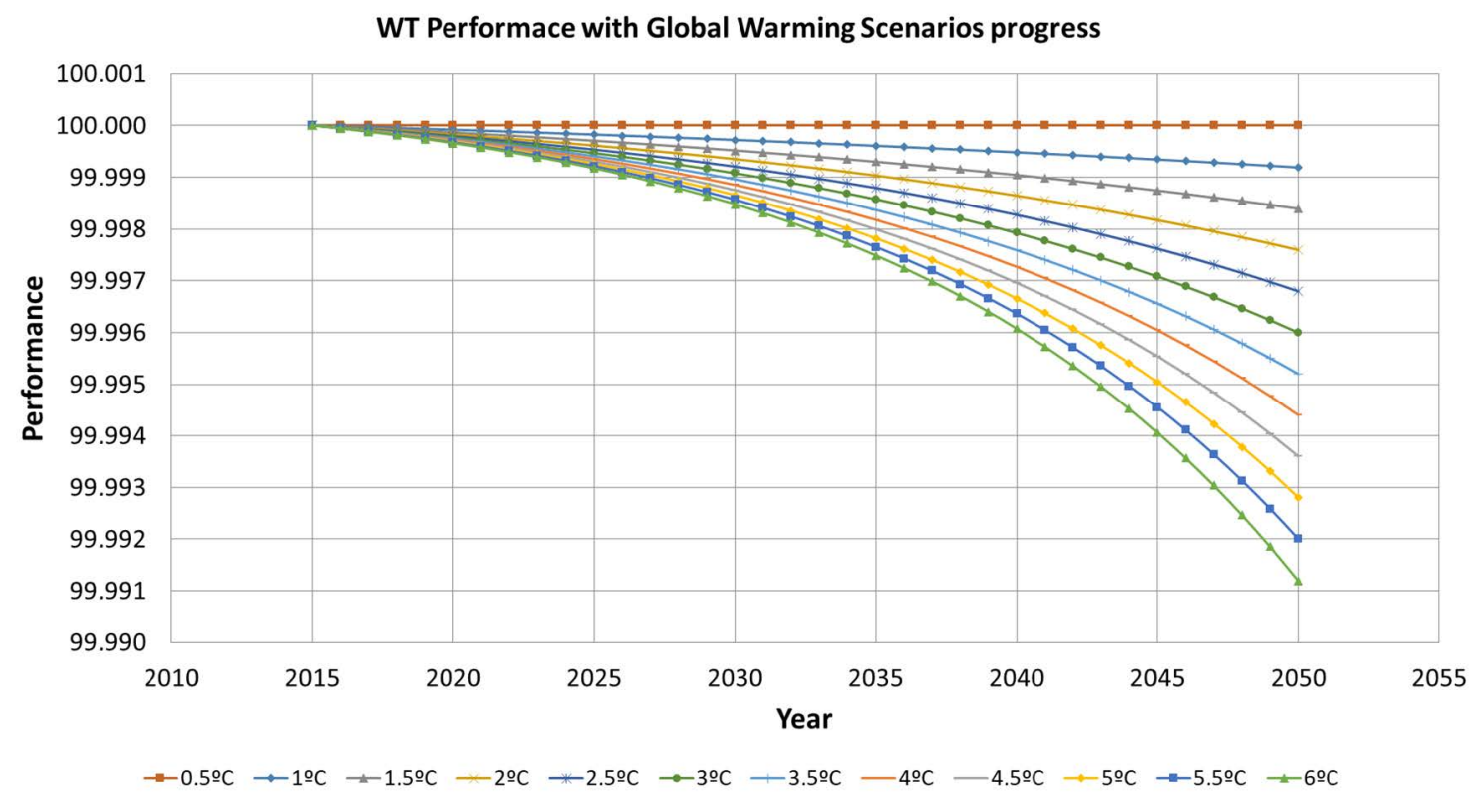

Figure 13. Performance curve over time vs. global warming temperature. 
In Figure 13, it is observed how the loss of performance in the worst-case scenario will not be representative, with Performance $(\%){ }_{6}{ }^{\circ} \mathrm{C}$ being equal to $99.99 \%$.

It is possible to estimate the economic loss of the installation used for this paper from Equation (18), which jointly considers the performance loss and the thermal evolution presented in Figure 12. The performance loss will affect the balance sheets of the companies that operate the wind farms, since their revenues will be reduced for a period of 30 years. This is the amortization period which is typically required for new renewable energy plants with life-cycle extension systems. A performance loss of $0.0024 \%$ per year, for similar turbines deployed after 2050 , results in a $0.072 \%$ accumulated loss over the life cycle. This represents USD 655 (2018 USD) for a standard 1.5MW wind turbine in a site with 2700 full-load hours [32,33] (we have assumed an expected average electricity selling price in the EU of EUR 158 (2013)/MWh for the period 2030-2050, according to [21]. OECD exchange rates have been used [22]). However, it is necessary to analyze the gradual loss of performance of the installation under study during the global warming process. The energy lost during the period 2015-2050 has been calculated in monetary terms taking into account the loss of performance in each year (which depends on the global warming of each scenario) and multiplying it by the installed capacity of the wind farm (30MW) and the production ratio (2067 equivalent hours for this wind farm). The results are shown in Table 1 . The loss (in terms of the electricity which would not be generated) would be USD 12,000 in the case of 2 degrees of global warming and USD 43,000 (2018 USD) in the case of 6 degrees.

Table 1. Summary of the global warming effects for the wind farm.

\begin{tabular}{|c|c|c|c|c|}
\hline $\begin{array}{c}\Delta T\left({ }^{\circ} \mathrm{C}\right) \\
\text { (from 1990) }\end{array}$ & Performance (\%) & Lost Energy MWh & $\begin{array}{l}\text { Lost Incomes } \\
\text { (kUSD) '18 * }\end{array}$ & $\begin{array}{c}\text { Additional } \\
\mathrm{ktCO}_{2}^{* *}\end{array}$ \\
\hline 0.5 & 100 & 0 & 0 & 0 \\
\hline 1.0 & 99.9992 & 17.4 & 3.9 & 5.7 \\
\hline 1.5 & 99.9984 & 34.7 & 7.8 & 11.5 \\
\hline 2.0 & 99.9976 & 52.1 & 11.7 & 17.2 \\
\hline 2.5 & 99.9968 & 69.4 & 15.59 & 22.9 \\
\hline 3.0 & 99.9960 & 86.8 & 19.49 & 28.6 \\
\hline 3.5 & 99.9952 & 104.2 & 23.39 & 34.4 \\
\hline 4.0 & 99.9944 & 121.5 & 27.29 & 40.1 \\
\hline 4.5 & 99.9936 & 138.9 & 31.18 & 45.8 \\
\hline 5.0 & 99.9928 & 156.3 & 35.08 & 51.6 \\
\hline 5.5 & 99.9920 & 173.6 & 39.98 & 57.3 \\
\hline 6.0 & 99.9912 & 191 & 42.9 & 63.0 \\
\hline
\end{tabular}

Furthermore, the wind electricity which is not generated will need to be produced by other sources in order to avoid supply cuts. This will lead to an increase in GHG emissions if these other generation sources are fossil-fuel fired. Assuming the electricity mix in Spain (with a large share of renewables), the average emissions from electricity generation would be $0.33 \mathrm{tCO}_{2} / \mathrm{kWh}$. Therefore, $17,000 \mathrm{tCO}_{2}$ will have been emitted in 2050 in the case of 2 degrees of global warming $\left(63,000 \mathrm{tCO}_{2}\right.$ in the case of 6 degrees).

\section{Discussions}

The impact of environmental temperature on the production of a wind farm has been analyzed in this paper. A model of the electricity which can potentially be generated by wind turbines, taking into account both the wind speed and the temperature at the site, has been developed. The method allows simulating the impact of the average thermal increases due to global warming. Using a complex model of wind energy generation based on ANN and Fuzzy logic rules, the reduction in the performance of the wind farm and, thus, the reduction in electricity generation from wind, can be calculated.

Our results show that an increase in temperatures will trigger a reduction in the performance of wind turbines. However, the impact of temperature increases on wind energy performance will 
probably be modest, since the wind turbine control system is able to correct the wind energy loss through adjustments in the angle of the wind blades.

Climate change and energy models, and particularly integrated assessment models, should take the bidirectional impact of temperature increases and (wind) electricity generation into account. The changes (increase or reduction) in potential electricity generation from wind that can be expected as a result of higher temperatures should be included in these models. The methodology developed in this paper provides a useful contribution in this regard, since it could be added to existing integrated assessment models.

Further research could be devoted to the analysis of other possible effects, including changes in the features of winds, lower availability of equipment and extensions to other RETs. First, the impact of changes in the features of winds (frequency, direction and intensity) should be analyzed. Global warming can be expected to extend the summer season, which is when the winds are softer.

Second, the increase in average temperatures will reduce the availability of wind energy equipment. Such an increase will lead to more frequent overheating of the equipment which, in turn, will lead to more frequent shutdowns of the wind turbines in order to cool some components. The availability of the equipment will be reduced. In addition, electricity consumption due to cooling as well as the electricity losses in wires, transformers and generators will increase. A thermal increase could also accelerate the degradation of some components, including oils, bearings, windings, etc., which would increase the operational costs.

Finally, the methodology used in this article should be applied to different wind turbine technologies and to installations located in different places around the world. However, this will be the focus of future research, since the operation data which would be required for such analysis are not currently available. The analysis can also be extended to other renewable energy technologies and, in particular, to solar PV. It is likely that the performance losses will be higher for this technology than for wind (given the absence of control devices, as it is the case with wind turbines).

Author Contributions: Conceptualization, M.Á.R.-L., E.C. and P.d.R.; methodology M.Á.R.-L., E.C. and P.d.R.; software, M.Á.R.-L.; validation M.Á.R.-L., E.C. and P.d.R.; formal analysis, M.Á.R.-L.; investigation, M.Á.R.-L., E.C. and P.d.R. resources, M.Á.R.-L.; data curation, M.Á.R.-L.; writing—original draft preparation, M.Á.R.-L., E.C. and P.d.R.; writing—review and editing, P.d.R., E.C. and M.Á.R.-L.; visualization, E.C. and P.d.R.; supervision, E.C. and P.d.R. All authors have read and agreed to the published version of the manuscript.

Funding: This research received no external funding.

Conflicts of Interest: The authors declare no conflict of interest.

\section{References}

1. Edenhofer, O.; Sokona, Y.; Seyboth, K.; Eickemeier, P.; Matschoss, P.; Hansen, G.; Kadner, S.; Schlömer, S.; Zwickel, T.; von Stechow, C. (Eds.) Special Report on Renewable Energy Sources and Climate Change Mitigation 2016; Intergovernmental Pannel on Climate Change (IPCC): Geneve, Switzerland, 2016; ISBN 978-92-9169-131-9. Available online: https://www.ipcc.ch/pdf/special-reports/srren/SRREN_FD_SPM_final.pdf (accessed on 10 July 2019).

2. Schreurs, M.A. Breaking the impasse in the international climate negotiations: The potential of green technologies. Energy Policy 2012, 48, 5-12. [CrossRef]

3. Global Wind Energy Council (GWEC). Global Installed Wind Power Capacity. 2012. Available online: http://www.gwec.net/wp-content/uploads/2012/06/Global-Installed-Wind-Power-Capacity-MW-\%E2\%80\% 93-Regional-Distribution.jpg (accessed on 16 January 2020).

4. Global Wind Energy Council. Global Wind Report Annual Market Update 2015. 2016. Available online: http: //www.gwec.net/wp-content/uploads/vip/GWEC-Global-Wind-2015-Report_April-2016_22_04.pdf (accessed on 12 July 2019). 
5. International Energy Agency (IEA). World Energy Investment 2016; IEA: Paris, France, 2016.

6. Poponi, D.; Bryant, T.; Burnard, K.; Cazzola, P.; Dulac, J.; Pales, A.F.; Husar, J.; Janoska, P.; Masanet, E.R.; Munuera, L.; et al. Energy Technology Perspectives 2016; Towards Sustainable Urban Energy Systems; International Energy Agency: Paris, France, 2015; ISBN 978-92-64-25233-2.

7. Helbing, G.; Ritter, M. Improving wind turbine power curve monitoring with standardisation. Renew. Energy 2020, 145, 1040-1048. [CrossRef]

8. Kusiak, A.; Zheng, H.; Song, Z. On-line monitoring of power curves. Renew. Energy 2009, 34, 1487-1493. [CrossRef]

9. Wang, L.; Zhang, Z.; Xu, J.; Liu, R. Wind Turbine Blade Breakage Monitoring with Deep Autoencoders. IEEE Trans. Smart Grid 2016, 9, 2824-2833. [CrossRef]

10. Lu, L.; Yang, H.; Burnett, J. Investigation on wind power potential on Hong Kong islands-An analysis of wind power and wind turbine characteristics. Renew. Energy 2002, 27, 1-12. [CrossRef]

11. Ritter, M.; Deckert, L. Site assessment, turbine selection, and local feed-in tariffs through the wind energy index. Appl. Energy 2017, 185, 1087-1099. [CrossRef]

12. Cambron, P.; Lepvrier, R.; Masson, C.; Tahan, A.; Pelletier, F.; Tahan, A. Power curve monitoring using weighted moving average control charts. Renew. Energy 2016, 94, 126-135. [CrossRef]

13. Trivellato, F.; Battisti, L.; Miori, G. The ideal power curve of small wind turbines from field data. J. Wind. Eng. Ind. Aerodyn. 2012, 107-108, 263-273. [CrossRef]

14. Pelletier, F.; Masson, C.; Tahan, A.; Tahan, A. Wind turbine power curve modelling using artificial neural network. Renew. Energy 2016, 89, 207-214. [CrossRef]

15. Ata, R. RETRACTED: Artificial neural networks applications in wind energy systems: A review. Renew. Sustain. Energy Rev. 2015, 49, 534-562. [CrossRef]

16. Nayeripour, M.; Mansouri, M. An advanced analytical calculation and modeling of the electrical and mechanical harmonics behavior of Doubly Fed Induction Generator in wind turbine. Renew. Energy 2015, 81, 275-285. [CrossRef]

17. Fan, Z.; Zhu, C. The optimization and the application for the wind turbine power-wind speed curve. Renew. Energy 2019, 140, 52-61. [CrossRef]

18. Lydia, M.; Kumar, S.S.; Kumar, K.V.; Kumar, G.E.P. Wind resource estimation using wind speed and power curve models. Renew. Energy 2015, 83, 425-434. [CrossRef]

19. Marčiukaitis, M.; Zutautaite, I.; Martišauskas, L.; Jokšas, B.; Gecevičius, G.; Sfetsos, A. Non-linear regression model for wind turbine power curve. Renew. Energy 2017, 113, 732-741. [CrossRef]

20. Ouyang, T.; Kusiak, A.; He, Y. Modeling wind-turbine power curve: A data partitioning and mining approach. Renew. Energy 2017, 102, 1-8. [CrossRef]

21. Pryor, S.C.; Barthelmie, R.J. Climate change impacts on wind energy: A review. Renew. Sustain. Energy Rev. 2010, 14, 430-437. [CrossRef]

22. Fant, C.; Schlosser, C.A.; Strzepek, K. The impact of climate change on wind and solar resources in southern Africa. Appl. Energy 2016, 161, 556-564. [CrossRef]

23. Davy, R.; Gnatiuk, N.; Pettersson, L.; Bobylev, L. Climate change impacts on wind energy potential in the European domain with a focus on the Black Sea. Renew. Sustain. Energy Rev. 2018, 81, 1652-1659. [CrossRef]

24. Hosking, J.S.; MacLeod, D.; Phillips, T.; Holmes, C.R.; Watson, P.; Shuckburgh, E.F.; Mitchell, D. Changes in European wind energy generation potential within a $1.5{ }^{\circ} \mathrm{C}$ warmer world. Environ. Res. Lett. 2018, 13, 054032. [CrossRef]

25. Schlechtingen, M.; Santos, I.F.; Achiche, S. Wind turbine condition monitoring based on SCADA data using normal behavior models. Part 1: System description. Appl. Soft Comput. 2013, 13, 259-270. [CrossRef]

26. Kusiak, A.; Verma, A. Analyzing bearing faults in wind turbines: A data-mining approach. Renew. Energy 2012, 48, 110-116. [CrossRef]

27. Lydia, M.; Kumar, S.S.; Kumar, K.V.; Kumar, G.E.P. A comprehensive review on wind turbine power curve modeling techniques. Renew. Sustain. Energy Rev. 2014, 30, 452-460. [CrossRef]

28. Taslimi-Renani, E.; Modiri-Delshad, M.; Elias, M.F.M.; Rahim, N.A. Development of an enhanced parametric model for wind turbine power curve. Appl. Energy 2016, 177, 544-552. [CrossRef] 
29. Gil, A.; Sanz-Bobi, M.A.; Rodríguez-López, M.A. Behavior Anomaly Indicators Based on Reference Patterns-Application to the Gearbox and Electrical Generator of a Wind Turbine. Energies 2018, 11, 87. [CrossRef]

30. Lapira, E.; Brisset, D.; Ardakani, H.D.; Siegel, D.; Lee, J. Wind turbine performance assessment using multi-regime modeling approach. Renew. Energy 2012, 45, 86-95. [CrossRef]

31. National Aeronautics and Space Administration (NASA). Available online: http://climate.nasa.gov/system/ internal_resources/details/original/647_Global_Temperature_Data_File.txt (accessed on 16 January 2020).

32. European Union. EU Reference Scenario 2016, Energy, Transport and GHG emi4ssions Trend to 2050. Available online: https://ec.europa.eu/energy/sites/ener/files/documents/ref2016_report_final-web.pdf (accessed on 13 July 2019).

33. The Organisation for Economic Co-ope4ration and Development (OECD). Exchange Rates. Available online: https://data.oecd.org/conversion/exchange-rates.htm (accessed on 1 May 2019).

(C) 2020 by the authors. Licensee MDPI, Basel, Switzerland. This article is an open access article distributed under the terms and conditions of the Creative Commons Attribution (CC BY) license (http://creativecommons.org/licenses/by/4.0/). 